L. Israel J. Bot., v. 30 , p. $41-47,1981$.

JANZEN, D.H. How to be a fig. Ann. Rev. Ecol. Syst., v. 10, p. $13-51,1979$.

LISCI, M.; PACINI, E. Germination ecology of drupelets of the fig (Ficus carica L.). Bot. J. Linnean Soc., v. 114, p. 133-146, 1994.

MELLO-FILHO, L.E.; NEVES, L.J. Um caso de nostogamia em Ficus microcarpa L.f. Bradea, v. 5, p. 334-337, 1990.

MICHALOUD, G.; MICHALOUD-PELLETIER, S. Ficus hemiepiphytes (Moraceac) et arbres supports. Biotropica, v. 19, p. 125-136, 1987.

PEREIRA, F.M. Cultura da figueira. Piracicaba: Livroceres, 1981.
RAMIREZ, B., W. Germination of seeds of New World Urostigma (Ficus) and Morus rubra L. (Moraceae). Rev. Biol. Trop., v. 24, p. 1-6, 1976.

SAZIMA, I.; FISCHER, W.A.; SAZIMA, M.; FISCHER, E.A. The fruit bat Artibeus lituratus as a forest and city dweller. Ci. Cult., v. 46, p. 164-168, 1994.

TERBORGH, J. Keystone plant resources in the tropical forest. IN: Conservation biology (M.E. SOULE், ed.). Massachusetts: Sinauer, 1986.

WINDSOR, D.M.; MORRISON, D.W.; ESTRIBI, M.A.; DE LEON, B. Phenology of fruit and leaf production by strangler figs on Barro Colorado Island, Panama. Experientia, v. 45, p. $647-653,1989$.

ZAR, J. Biostatistical analysis. New Jersey: Prentice Hall, 1996 .

\title{
ESTUDO DA FLORA BACTERIANA NASAL: ESTUDO PRELIMINAR EM EQUIPE DE ENFERMAGEM
}

\author{
ROSANA EMIKOHESHIKI' \\ SERGIO RICARDO R. A. SANTOS ${ }^{1}$ \\ ZULEICA NAOMI TANO' \\ SILVIO SERGIO PONTES CÂMARA' \\ WELLINGTON ANDRAUS' \\ ZENSHI HESHIKI ${ }^{2}$ \\ REGINA M. B. QUESADA ${ }^{3}$ \\ MARISA KISSU* \\ MIRIAM MATSUDA4
}

HESHIKI, R.E. et al. Estudo da Flora Bacteriana Nasal: estudo preliminar em equipe de enfermagem. Semina:

Ci. Biológicas/Saúde, v. 17, n. 2, p. 191-196, jun. 1996.

RESUMO: Há pouca informação sobre o crescimento de microorganismos patogênicos na flora nasal em paises tropicais, já que grande parte das pesquisas se realizaram em paises de clima temperado. Neste estudo, identificamos a flora nasal da equipe de enfermagem dos Hospitais Universitários de Londrina, correlacionando os resultados com a literatura consultada e disponivel.

PALAVRAS-CHAVE: Flora Nasal, Staphylococcus aureus, Gram negativo, rinites enfermagem, taxa de portadores

\section{INTRODUÇÃo}

A importância epidemiológica dos portadores de organismos patogenicos em flora nasal tem sido uma constante preocupaçāo dos pesquisadores, embora sejam escassas as publicaçōes nacionais. Esta preocupação tem aumentado nos últimos anos, principalmente em relaçāo aos profissionais do meio hospitalar. Isto se deve ao fato de serem as fossas nasais um nicho com elevada possibilidade de colonização e de dispersâo de bactérias.

\section{REVISÃO BIBLIOGRÁFICA}

Hutchison e cols. (1957) estudaram grupos de enfermeiras em treinamento para determinar o efeito da mudança de ambiente no transporte nasal de Staphylococcus aureus. Observaram cepas mais resistentes que as da população geral, principalmente nos indivíduos submetidos a maior exposiçāo.

White (1961) estudou as culturas nasais de pele e de amostras de ar de 250 pacientes hospitalizados mostrando porcentagem significante de Staphylococcus

1 - Ex-alunos de Medicina da UEL

2 - Docente da disciplina de Otorrinolaringologia do HURNPR (UEL)

3 - Docente da microbiologia e Chefe do Laboratório de Análises Bioquímicas do HURNPR

4 - Alunas de Farmácia e Bioquímica da UEL 
sp em pele de pacientes que também eram portadores nasais. O'Grady e Witthstadt (1963) estudaram a possivel relação da presença de Staphilococcus aureus nas fossas nasais com outras bactérias.

Maxwell e cols. (1969) estudaram Staphylococcus aureus em populaçāo hospitalar por um período de 6 anos, observando $33 \%$ de portadores na equipe cirúrgica e ausência da bactéria em $42 \%$.

Johanson e cols. (1969) estudaram bactérias Gram (-) nas fossas nasais.

Rahal e cols. (1970) demonstraram a incidência de portadores nasais e faríngeos de bactérias Gram ( - ) entre a equipe médica, comparando com os empregados que não tinham contato com pacientes. Concluiram nāo haver diferença entre as duas populaçōes. Çetin e cols. (1970) estudaram as floras de oro e nasofaringe de estudantes de medicina, farmácia, odontologia e ciências, sem encontrar diferenças entre os mesmos.

Doig (1971) identificou estafilococo em $50 \%$ de pacientes internados na unidade de cirurgia geral e $26 \%$ nos pacientes ambulatoriais. Entre a equipe de médicos e enfermeiras obteve cerca de $80 \%$.

Winther e cols. (1974) descrevem que complicaçōes sérias após infecçōes graves ocorrem mais frequentemente em individuos portadores de flora bacteriana prévia.

Heczko e cols. (1981) estudaram a flora aeróbia e nāo aeróbia de membros de equipe laboratorial. A presença de Staphylococcus aureus foi relacionada com a diminuiçāo do número de outras cepas estafilocócicas.

Zelante e cols. (1982-83) pesquisaram a presença de Staphylococcus aureus em nariz, saliva e raspado lingual em indivíduos clinicamente sadios e obtiveram $36.15 \%$ de positividade

Kingdom e cols. (1983) estudaram a flora nasal de alunos de medicina, verificando haver aquisiçāo de múltiplas cepas resistentes com o aumento da exposiçāo hospitalar ao final do curso.

Weil e cols (1984) pesquisaram a cultura de māos e narinas de equipe farmacêutica, mostrando que a exposiçaó aos antibióticos não foi suficiente para aumentar as taxas de colonizaçāo de nariz ou de contaminaçāo de māos com bacilos Gram ( - ).

Lamikanra e cols. (1985) demonstraram o decréscimo do número de hospedeiros de Staphylococcus aureus com o aumento da idade, e que indivíduos do sexo feminino possuiam uma maior taxa de colonizaçāo. Seus resultados foram $56.4 \%$ de positividade global.

Barth e cols. (1987) fizeram uma revisäo sobre a flora nasal no neonato e relatam que Staphylococcus aureus pode ser isolado em flora nasal quando há infeç̧ăo sistêmica pelo mesmo agente. Chow e cols. (1989) estabeleceram relaçäo entre portadores nasais de Staphylococcus aureus e infecçōes de pacientes submetidos à diálise peritonial.

Gittelman e cols. (1990) identificaram como um dos fatores de risco para o desenvolvimento da Sindrome do choque tóxico a condiçăo de portador de Staphylococcus aureus produtor de exotoxinas.

Cedema e cols.(1990) observaram a eficácia da mupirocina na erradicaçāo de Staphylococcus aureus em pacientes de asilos.

\section{MATERIAL E MÉTODO}

Coletou-se amostras de 80 pessoas da equipe de enfermagem, sendo que destas, 20 trabalhavam em regime ambulatorial no Hospital de Clínicas e $60 \mathrm{em}$ regime hospitalar no Hospital Universitário Regional do Norte do Paraná, ambos pertencentes à Universidade Estadual de Londrina. As secreçōes foram obtidas introduzindo-se a zaragatoa (swab) em uma das fossas nasais, tomando-se o cuidado de deixa-las durante dois minutos. O material foi passado em lâmina para realizaçāo de bacterioscopia, e inoculado em Stuart Medium (meio de transporte).

Do Stuart Medium, já no Laboratório, as amostras foram semeadas em Agar Sangue e a zaragatoa inoculada em TSB (Triptic Soy Broth da DIFCO) e mantidos incubados a $35 \pm 2^{\circ} \mathrm{C}$ durante 18 a 24 horas.

Após a incubaçäo, as colônias desenvolvidas no Agar Sangue foram submetidas à coloraçāo de Gram e às provas bioquímicas especificas para bactérias Gram negativas e/ou Gram positivas. Do caldo TSB foram repicados em Agar Manitol Sal-vermelho de Fenol (MERCK) e MacConkey Agar (MERCK) e após incubaçāo "over night" a $35 \pm 2^{\circ} \mathrm{C}$ as colônias foram submetidas às provas bioquimicas especificas para identificaçāo do microorganismo isolado.

\section{4-RESULTADOS}

Para facilitar o estudo, apresentamos os resultados em forma de Quadros.

Somente $2,5 \%$ das coletas foram negativas. Em $61.25 \%$ da populaçāo apresentou crescimento de apenas uma bac-téria. Em $30 \%$, verificou a presença de 2 bactérias. Esta cifra atinge $91.25 \%$ com 1 ou 2 bactérias (Quadro 1). Em alguns casos foram identificadas até três espécies.

Foram isoladas 19 bactérias de interesse médico na flora nasal da população estudada. (Quadro 2). Para facilitar a análise agrupamos em Staphilococcus, Gram ( - ) e Streptococcus.

Em 71 dos 80 individuos $(88.75 \%$ ) hospedavam alguma espécie de Staphylococcus, dos quais 17 $(21,25 \%)$ eram portadores de Staphylococcus aureus.

Em 35 dos $80(43.75 \%)$ hospedavam germes Gram negativos.

Foram detectados somente $1.25 \%$ de Streptococcus. 


\section{Quadro 1 - FLORA BACTERIANA DA FOSSA NASAL}

Número de bactérias isoladas por pessoa

\begin{tabular}{ccc}
\hline № de bactérias & № pessoas & $\%$ \\
0 & 02 & 02.50 \\
1 & 49 & 61.25 \\
2 & 24 & 30.00 \\
3 & 05 & 06.25 \\
\hline TOTAL & 80 & $100.00 \%$ \\
\hline
\end{tabular}

Quadro 2 - BACTÉRIAS ISOLADAS DA FLORA NASAL

\begin{tabular}{|c|c|c|c|}
\hline Agente & Total & $\%$ & $\%($ Amostra $)$ \\
\hline Staphylococcus sp & $\underline{73}$ & $\underline{64.6}$ & $88.75(71 / 80)$ \\
\hline 01-Staphylococcus epidermides & 52 & 46.02 & 65.00 \\
\hline 02-Staphylococcus aureus & 17 & 15.04 & 21.25 \\
\hline 03-Staphylococcus saprophyticus & 04 & 3.54 & 5.00 \\
\hline Bactérias GRAM (-) & $\underline{39}$ & $\underline{34.51}$ & $43.75(35 / 80)$ \\
\hline 04-Enterobacter aerogenes & 08 & 7.08 & \\
\hline 05-Escherichia coli & 03 & 2.65 & \\
\hline 06-Klebsiella pneumoniae & 06 & 5.30 & \\
\hline 07-Klebsiella ozonae & 03 & 2.65 & \\
\hline 08-Klebsiella oxytoca & 01 & 0.89 & \\
\hline 09-Citrobacter diversus & 02 & 1.77 & \\
\hline 1Q-Pseudomonas aeruginosa & 02 & 1.77 & \\
\hline 11-Proteus mirabilis & 02 & 1.77 & \\
\hline 12-Proteus vulgaris & 02 & 1.77 & \\
\hline 13-Enterobacter cloacae & 02 & 1.77 & \\
\hline 14-Enterobacter sp & 01 & 0.89 & \\
\hline 15-Acinetobacter calcoaceticus & 03 & 2.65 & \\
\hline 16-Bacillus sp & 02 & 1.77 & \\
\hline 17-Micrococcus sp & 01 & 0.89 & \\
\hline 18-Serratia phymatica & 01 & 0.89 & \\
\hline 19-Streptococcus Beta hemolítico & $\underline{01}$ & 0.89 & $1.25(1 / 80)$ \\
\hline TOTAL & 113 & $100.00 \%$ & \\
\hline
\end{tabular}




\begin{tabular}{cc}
\hline Quadro 3 - & FLORA BACTERIANA NASAL: \\
& Resultados comparativos entre diferentes autores
\end{tabular}

Staphylococcus aureus

\begin{tabular}{|c|c|c|c|c|c|}
\hline Autores & Ano & Amostras & \multicolumn{2}{|c|}{ CulturaTipo pop. } & No coletas \\
\hline Maxwell & 1949 & $57.50 \%$ & $* \star \star *$ & enfermagem & seriado \\
\hline Hutchison & 1957 & $56.90 \%$ & $* * * *$ & enfermagem & seriado \\
\hline White & 1961 & $37.11 \%$ & $* * * *$ & paciente.int & unica \\
\hline Çetin & 1970 & $11.00 \%$ & $* * * *$ & estudante medic. & unica \\
\hline Doig & 1971 & $26.00 \%$ & $* \star * *$ & paciente ambulat. & unica \\
\hline & & $50.00 \%$ & $* * * *$ & paciente internado & unica \\
\hline & & $80,00 \%$ & $* * * *$ & medicos/enferm. & única \\
\hline Heczko & 1981 & $* * * *$ & $11.6 \%$ & laboratório & 6 vezes \\
\hline Zelante1982 & $36.15 \%$ & $* * * *$ & pacient & mais unica & \\
\hline Lamikanra & 1985 & $56.40 \%$ & $* * * *$ & est. $1^{\circ}-2^{\circ}$ univers. & unica \\
\hline Chow & 1989 & $45.00 \%$ & $\star * \star \star *$ & paciente pre dialise & unica \\
\hline Cederna & 1990 & $38.20 \%$ & $* * * *$ & $\begin{array}{l}\text { paciente asilo unica } \\
\text { nas) }\end{array}$ & \\
\hline Heshiki & 1995 & $21.25 \%$ & $15.04 \%$ & enfermagem & unica \\
\hline
\end{tabular}

Staphylococcus epidermides

\begin{tabular}{lllllll} 
Autores & Ano & Amostras & & \multicolumn{2}{c}{ CulturaTipo pop. } & № coletas \\
Heczko & 1981 & **** & & $30.9 \%$ & laboratório & 6 vezes \\
Heshiki & 1995 & $46.02 \%$ & & $65.0 \%$ & enfermagem & única
\end{tabular}

Gram (-)

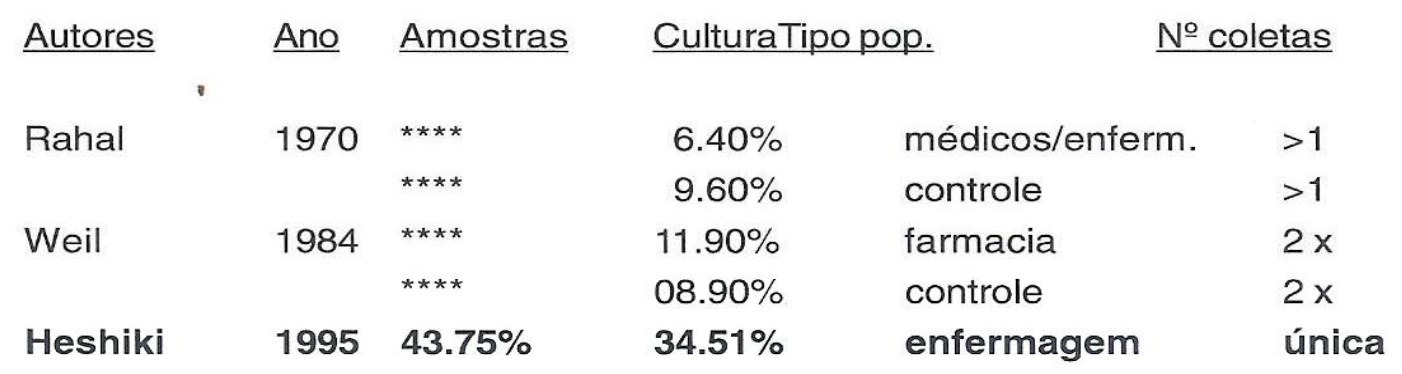

Streptococcus

$\underline{\text { Autores Ano Amostras }}$ CulturaTipopop. № coletas

\begin{tabular}{llllll} 
Gittelman & 1991 & $8.00 \%$ **** & \multicolumn{2}{c}{ pac. rinossinusite única } \\
Heshiki & 1995 & $\mathbf{1 . 2 5} \%$ & $\mathbf{0 . 8 9 \%}$ & enfermagem & única \\
\hline
\end{tabular}




\section{5- DISCUSSĀO}

O Quadro 1 mostra que em mais de $90 \%$ fol possivel identificar 1 ou 2 germes patogenicos na fossa nasal da equipe de enfermagem dos nossos Hospitais.

$\mathrm{Na}$ literatura a incidência de Staphylococcus aureus variou de $11.0 \%$ (Çetin e col. 1970 ) a $80.0 \%$ (Doig1971 ) considerando diferentes tipos de agrupamentos de pessoas. Os primeiros autores analisaram as fossas nasais de 1112 estudantes de medicina e o segundo em amostras de 1354 pacientes internados, ambos colhidos em 1 única amostra. (Quadro 3 )

A incidência de Staphylococcus aureus não confere com as citadas na literatura. Podemos verificar que varia ao redor de $11 \%$ em pessoas que trabalham em laboratório e em estudantes de medicina. A cifra é de $38 \%$ nos internados em asilos ou $50 \%$ nos internados em hospital. Nosso material cuja população é de enfermagem, mostra $15 \%$ em relaçâo às culturas positivas ou $21 \%$ da populaçâo estudada (amostra). Hutchison e col (1957) e Maxwell e col. (1969) também colheram da equipe de enfermagem e detectaram $57 \%$, portanto muito acima em relaçāo aos nossos resultados. Doig (1971) detectou $80 \%$ em médicos e enfermeiras.

Os dados deste trabalho não coincidem com os encontrados na literatura. $O$ pequeno número de casos estudados pode explicar esta diferença, outro fator pode ser o número de coletas. Çetin e cols (1970) detectaram $11 \%$ de resultados positivos entre estudantes de medicina. Nós já estamos realizando estudos entre estudantes e podemos no futuro, confrontar com os resultados desses autores. Nos trabalhos, com amostras seriadas, foi possivel classificar os portadores em Persistentes, Intermitentes e Esporádicos. Portanto, isto pode também justificar a baixa incidência encontrada, já que năo foi possivel identificar a totalidade dos portadores Esporádicos e Intermitentes neste estudo. O estudo de Doig (1971) em pacientes internados $(50 \%)$ e ambulatorial (26\%) é muito interessante pois mostra a diferença significativa entre estes tipos de pacientes. Devemos destacar que poucos trabalhos foram publicados para estudar a flora nasal em países tropicais, o que poderia também justificar as diferenças entre os resultados obtidos. O fator climático pode ser a causa das diferenças. Podemos citar os trabalhos de Zelante e col. (1982-1983) e Lamikanra e col.(1985) que foram realizados em locais com clima semelhante ao nosso. Estes estudos também mostram diferenças com $36 \%$ e $56 \%$, em grupos aparentemente normais e sem contato com o meio hospitalar.

Em relaçāo ao Staphylococcus epidermides tivemos $46.02 \%$ das culturas e a incidência na população foi de $65 \%$. Heczko e col.(1981) observaram incidéncia de $30.9 \%$ das colônias isoladas a partir de 48 culturas de secreção de flora nasal em amostra de 8 membros efetivos de Laboratório. Existe diferença signiticativa, mas a metodologia empregada foi diferente.

A alta incidência de Gram negativos observada ( $43.75 \%$ na populaçăo e $34.5 \%$ das culturas) também nāo é compativel com os relatos na bibliografia consultada. Rahal e cols (1970) observaram positividade em $9.6 \%$ da população controle e $6.4 \%$ entre médicos e enfermeiras. Weil e cols (1984) mostram a incidência de portadores desses agentes na populaçāo geral de $9 \%$ e entre farmacêticos de $12 \%$. Os trabalhos de Johanson e col. (1969) e Rahal e col. (1970) relatam que a colonização por Gram negativos no trato respiratório superior nâo estaria relacionada à exposiçāo a estes agentes, mas sim à susceptibilidade de cada indivíduo em relação aos mesmos. Uma das possiveis explicaçóes para a alta incidência destes portadores em nosso meio pode ser o baixo nivel sócio-econômico da populaçăo o que pode levar a uma diminuição da resistência à colonizaçāo por Gram negativos. Outro fator sāo as condiçōes de trabalho da nossa população estudada.

Gittelman e cols (1990) constataram incidência de $8 \%$ de portadores de Streptococcus sp, dado superior ao encontrado neste trabalho que corresponde a $1.25 \%$ da populaçāo. Isso pode ser devido à má especificidade do Stuart Medium aos Streptococci. Barth (1987) em sua revisão sobre Streptococcus sp lembra que esses germes nâo são comuns no nariz, sendo seu habitat normal a faringe, e que o estado de portador nasal pode ocorrer após infecção clínica.

Devemos destacar, finalmente, que foram identificados 3 portadores de Acinobacter calcoaceticus $(2.65 \%)$ em funcionárias do Pronto Socorro. Merece destaque porque simultaneamente ocorreu um surto pelo mesmo agente na UTI do hospital motivando a interdição dessa unidade por varios dias. Nāo é possivel afirmar a correlaçāo entre estes fatos no presente estudo, mas merece ser citado para eventual pesquisa futura.

\section{6-CONCLUSŌES}

6.1- Em mais de $90 \%$ da equipe de enfermagem (população estudada), foram isolados um ou dois 
germes patogênicos nas fossas nasais.

$6.2-21.25 \%$ desta populaçāo é portadora de Staphylococcus aureus na flora nasal, cifra inferior comparadas com a literatura disponivel.

6.2- A incidência de Gram ( -) foi de $43.75 \%$, altamente superior aos niveis relatados na literatura.
6.3- A incidência de Streptococcus spfoi baixa em nosso material $(1.25 \%)$.

6.4- Foram identificados 3 casos $(2,77 \%)$ de Acinobacter calcoaceticus em pessoas que trabalhavam no Pronto Socorro na epoca em ocorreram diversos casos na UTI necessitando a interdiçāo da mesma.

HESHIKI, R.E. et al, Preliminary study of the nasal flora in nursing staff. Semina: Ci. Biológicas/Saúde, v. 17, n. 2, p. 191-196, Jun. 1996.

ABSTRACT: There are few information about the growth of patogenic microorganism of the nasal flora in tropical countries since most investigations were held in places with other climate. In this study, we identify the nasal flora of the nursing staff of Londrina State University Hospitals correlating the results with the information obtained worldwide.

KEY-WORDS: Nasal Flora, Staphylococcus aureus, Gram negative, rhinitis, Nursing staff, carrier rate.

\section{7-REFERÊNCIAS BIBLIOGRÁFICAS}

BARTH,J.H.; Nasal carriage of Staphylococci and Streptococci. Int. J. Dermatol. 26(1):24/26:1987.

CEDERNA,J.E.; TERPENNING,M.S.; ENSBERG,M. BRADLEY,S.F.; KAUFFMAN, C.A. Staphylococcus aureus nasal colonization in a nursing home: eradication with mupirocin. Infect. Control Hosp. Epidemiol. 11(1) $13 / 16: 1990$

ÇETIN, E.T.; ANG,O.; TORECl,K.; BERKITEN,R. Investigations on Aerobic Oral and Nasal Flora of University Students. Path. Microbiol. 37:185/193.- 1970

CHOW,J.W. ET ALLI. Staphylococcus aureus nasai carriage in hemodialysis patientes. Its role in infection and approaches to prophylasis. Arch. Internat. Med. 149:1258/1262-1989.

DOIG,C.M. Nasal carriage of Staphylococcus aureus in a general surgical unit Brit. J. Surg, $58(2)$ : 113/116 -1971

GITTELMAN,P.D.; JACOBS,J.; LEBOWITZ,A.S.; TIERNO,P.M. Staphylococcus aureus nasal carriage in patients with rhinosinusitis. The Laryngoscope 101(7) 733/737. 1991

HECZKO, P.B.; HOFFLER, U.; KASPROWICZ, A.; PULVERER,G. Quantitative studies of the flora of the nasal vestibule in relation to nasal carriage of Staphylococcus aureus. J. Med. Microbiol. 14:233/241 1981.

HUTCHISON, J.G.P.; GREEN, C.A.; GRIMSON, T.A. Nasal carriage of Staphylococcus aureus in nurses. J. Clin. Path. 10: $92 / 951957$

JOHANSON,W.G.; PIERCE,A.K. SANFORD,F.P. Changing pharyngeal bacterial flora of hospitalized patients. New Eng. J. Med. 281:1137/1140, 1969.

KINGDOM, J.C.P; JOYCE,S.M; BRADLEY,F.L.; JAUCH,W.; FALKINER,F.R.; KEANE,C.T. Staphylococusl aureus nasal carriage in medical students with varying clinical exposure J.Hosp.Infection (4):75/79-1983

LAMIKANRA,A.; BARBARA,D.P.; OMOLABAKEB.A.; PAUL, M.O. Nasal carriage of Staphylococcus aureus in a population of healthy nigerian students. J. Med. Microbiol. 19(2): 211/216, 1985.

MAXWELL, J.G.; FORD, C.R.; PETERSON,D.E.; MITCHELL,C.R. Long term Study of Nasal Staphylococci among Hospital personnel. Am. J. Surg. 118: 849/854,1949.

O'GRADY, F. WITTHSTADT, F.B. -Nasal carriage of Staphylococcus pyogenes Am. J. Hyg, 77:187/194.-1963

RAHAL,J.J.; MEADE, R.H.; BUMP, C.M.; REINAUER,A.J. Upper Respiratory Tract Carriage of Gram Negative Enteric Bacilit by Hospital Personnel. JAMA 214(4): 754/7561970

WEIL,D.C , ARNOW,P.M. Prevalence of gram negative bacilli in nares and on hands of pharmacy personnel: lack of effect of occupational exposure to antibiotics J. Clin. Microbiol. 10(5): 933-35, 1984

WHITE, A. Relation between quantitative nasal cultures and dissemination of staphylococci.

J. Lab. \& Clin. Med. 58(2): 273-277-1961

WINTHER.F.O.; HORTHE,A.; LYSTAD; VELLAR,D.O. Pathogenic bacterial flora in the upper respiratory tract of health students. J. Laryng. Otol. 88: 407/412.1974

ZELANTE,F.; ASHCAR, H.; PIOCHI,B.J.A.; MONSON, C.A.; CUNHA,P.S. Staphylococcus aureus na boca e no nariz de indivíduos sâos. Verificaçâo de identidade entre as cepas isoladas. Rev. Saúde Publ. 16:92/96-1982

ZELANTE, F.; ASHCAR, H,; PIOCHI, B.J.A.; ALVES, M.P.Observaçōes sobre o padrâo fágico de cepas de Staphylococcus aureus isoladas da boca e do nariz de individuos sāos. Rev. Saúde Publ. 17:123-9-1983. 